\title{
Comparison of Fecal, Rumen and Utilization Methods for Ascertaining Pronghorn Diets
}

\author{
A.D. SMITH AND L.J. SHANDRUK
}

\begin{abstract}
Fourteen male pronghorn (Antilocapra americana), two in each of seven spring and summer months, were killed to obtain rumen and fecal matter for comparing methods of determining diets. They came from a herd confined to the Desert Experimental Range in southwestern Utah. Animals were killed only after they had completed their early morning grazing period. Plant material was removed from the rumens and rectums, fresh feces were collected from the feeding site, and forage utilization and production estimates were made there. Diets as indicated by the four data sources-rumen, intestinal feces, site feces, and utilizationvaried with individual animals from close to little agreement, a not unexpected result in view of food availability and selection. Fewer plant species were identified by fecal analysis than were found in the rumen; even fewer species were recorded by utilization estimates. This indicates that fecal analysis may be less accurate than rumen data but more so than those based on plant utilization. Validation tests of the fecal method conducted with mule deer (Odocoileus hemionus) fed known diets showed substantial differences with individual species in the amounts fed and the amounts indicated by fecal analysis. Only in the case of the single grass species fed was there close agreement; browse and forb species differed greatly.
\end{abstract}

Effective management of wild ruminants and their habitat depends upon a knowledge of plants selected and the composition of the diet at each season. All methods for determining animal diets have disadvantages. Analyses of rumen contents necessitate sacrificing animals unless fistulated animals are available, a costly and often troublesome procedure. Moreover, biased estimates may result from rumen samples because plants have different rates of digestibility and disappearance from the rumen. Utilization estimates, usually ocular, are subject to observer error and personal biases. Utilization is difficult to detect when use is light, as it often is with game animals; and when more than one herbivore is present it may not be possible to separate their effects. There are limited opportunities for observing wild animals feeding at close range. In dense vegetation, determining the plant being utilized is nearly impossible. Use of tamed animals can minimize some of these difficulties, but they provide limited and possibily unrepresentative sampling.

Fecal analysis is increasingly advocated to avoid the disadvantages of other methods for determining diets of free-

\footnotetext{
Authors are with the Range Science Department, Utah State University, Logan. Utah St.321, and the Department of Environment, Canadian Wildlife Service, Edmonton, Alberta T5J iS6 Canada.

The research reported here was conducted in connection with a cooperative research program involving the Range Science Department, Utah State University, Utah State Division of Wildlife Resources, and Federal Aid to Wildlife Restoration, Project 105-R. Authors wish to express thanks to Intermountain Forest and Range Experiment Station for making facilities available for the study.

Manuscript received June 6. 1958.
}

ranging ruminants present. Fecal samples can be obtained without intensive animal observations, topography or dense vegetation is no hindrance, animals need not be killed or their normal feeding habits disrupted, and animal movements are unaffected. For these reasons the fecal method may be especially useful for determining the food habits when rare or endangered ruminants are involved.

It seemed worthwhile to inquire into the utility of the fecal analysis technique for determining pronghorn diets because: populations are sparse in Utah making direct observation difficult; their habit of defecating on roadways makes fecal collection comparatively easy even though animals are scattered widely; grass makes up a small part of their diets and past research in which the fecal technique has been used has dealt with animals whose diets were primarily grass.

The histological approach to food habits utilizing epidermal fragments in feces was first attempted by Dusi (1949) to determine food habits of rabbits by adapting a technique used by Baumgartner and Martin (1939) to analyze stomach contents from squirrels. Martin (1955) in Scotland and Croker (1959) and Hercus (1960) in New Zealand used fecal analysis to ascertain sheep diets. Voth and Black (1973) used the technique with mountain beaver (Aplodontia rufa) and Owen (1975) applicd it in waterfowl studics.

Despite the wide use of fecal analyses in food habits research, controlled tests using known diets are comparatively few. Storr (1961) used the fecal analysis technique to determine kangaroo diets using captive animals fed known diets. There was no significant digestion where epidermal tissue was well encased in cutin; a condition existing only in perennials. Annuals did not fill this requirement and the method did not "cope satisfactorily" with them.

Stewart (1967) fed known quantities of eight grasses to seven East African game species-six ruminants and one nonruminant. Counts of epidermal fragments were judged invalid because of their differential size. Determination of areas of epidermis or tabulations by point counts provided better indexes, but even then significant differences were found from the amounts ingested. Zyznar and Urness (1969) fed known quantities of shrub and herbaceous plant species to captive mule and white-tailed deer. Only a small percentage of the fecal material examined could be identified, leading them to question the accuracy of the method, although their techniques were less sophisticated than those developed since.

Free et al. (1970) collected forage samples from esophageally fistulated steers and fed the samples to sheep. They reported substantial agreement between the weights of grass species found in the esophageal samples and those in the fecal samples of steers and sheep. Forbs were less readily identifiable al- 


\section{though they were present in only small amounts.}

Hansen (1971) claimed close agreement between the composition of ingested and fecal material of wild sheep, but no data on plant species were included. Casebeer and Koss (1970) reported similarity between the stomach contents and fecal material of wildebeest (Connachaetes taurinas), zebra (Equus burchelli), hartebeest (Acelaphus buselaphus cokii), and cattle; but examination of their data show Themeda triandra was consistently over- or under-estimated depending on the animal and the season-in one case more than $200 \%$. Anthony and Smith (1974) compared rumen and fecal samples from both mule and white-tailed deer and found some highly significant differences.

Marshall (1969) warned of the difficulties encountered in the use of microscopic fecal analysis for quantifying herbivore diets. Slater and Jones (1971) reported that white clover in quantities up to $20 \%$ of the diet of sheep did not show up in the feces, and a grass species (Setaria sphacelata) which comprised 27 to $38 \%$ of the diet of three heifers yielded only 1 to $4 \%$ in the feces. Siratro, a legume, the only other plant in the diet suffered excessive fragmentation, which depressed the percentage of grass.

More recently, Jacobs (1973) reported results and problems of the fecal technique with pronghorn. He found smooth bromegrass (Bromus inermis), white sweetclover (Melilotus officinalis), and big sagebrush (Artemisia tridentata) were underestimated by the fecal technique. Westoby et al. (1976) concluded after examining ground contents from stomachs of jackrabbits (Lepus californicus) that the microscopic examination of fragmented material was ill suited to diets containing desert (northern) shrubs.

The primary objectives of this study were to:

1. Compare fecal analyses, rumen analysis, and utilization estimates as methods for obtaining quantitative estimates of antelope diets which are primarily of species other than grass.

2. Determine if various plant species representative of antelopes ${ }^{\circ}$ diets are differentially recognizable after passing through the digestive system of an animal.

\section{Methods}

The study was done in two phases. One involved killing pronghorn antelope from an experimental herd confined within an enclosure on the Desert Experimental Range in southwestern Utah, a branch of the Intermountain Forest and Range Experiment Station, U.S. Forest Service. Rumen and fecal materials were obtained from the killed animals by sampling the contents of the rumen and rectum. Two animals were taken each month from July to November in 1970, and in 1971 two animals were killed in April and two in June. A feared shortage of males-all animals taken were males-caused us to skip a planned May collection.

Animals were collected only after a herd of pronghorn numbering from a few to several animals had been observed to occupy and feed on a site for several hours. Forage utilization and production estimates for calculating diets were made at the feeding site, and fresh-appearing fecal material was collected from the immediate area.

Four different sources of data were thus available for comparison: rumen material, intestinal feces, feces collected from the ground, and vegetation estimates. Obviously these material sources were not entirely comparable, but no sample from an individual animal is comparable to that from another unless both are restricted to the same forage choices, an impossibility with free-ranging animals.

The rumen materials were analyzed by gravimetric point frame (described by Chamrad and Box 1964) and the microscopic point method. The microscopic-point count was accomplished by passing slides containing ground material under the objective of a compound- binocular microscope so that the cross hair described five equally spaced transects through the mount. Fragments encountered by the cross hair were identified and tabulated (Shandruk 1975). The point frame and microscopic point methods provided counts of fragments which were converted to percentage frequency. In this paper the means of the three methods were used to represent rumen analysis. To avoid observer biases all the samples were analyzed by one technique at a time in this order: rumen, intestinal fecal, and site fecal.

The dried fecal materials were ground through a 40 -mesh screen. The ground material was preliminarily treated as described by Storr (1961), Williams (1969), and Cavender and Hansen (1970). None of these procedures proved suitable, as the forb species in particular lost their distinguishing characteristics, making identification questionable. Furthermore, the procedures were too complicated and time consuming. The procedures used combined features of several techniques reported in the literature. A mixture of $10 \%$ nitric and chromic acids (1:1) was used to digest the ground (40-mesh screen) samples and free the epidermal fragments. Digestion lasted 12 hours. Safarin-0 and crystal violet stain were successively used as staining media. Stained materials were mounted on microscopic slides in Karo mounting medium. The procedures followed are described in detail by Shandruk (1975).

Although comparing the values obtained from the fecal material with those obtained by other methods provided a rough measure of the reliability of the fecal analysis technique, no definitive assessment could be made from these comparisons alone. Accordingly, a feeding test was devised where there was control over the species ingested. The test was conducted in May with green herbaceous forage. No pronghorn were available, so captive mule deer were used. Five plant species were included in the diet-two browse species, two forbs, and one grass (Table 3 ). The mixture used was formed to simulate the kinds of forage used by pronghorn. Only the browse species were identical to species found in the area from which the pronghorn were collected; the herbaceous species, however, were similar to or were of the same genera as plants available to them.

Two mule deer were confined to individual pens and fed ad libitum of the five species for several days to ascertain how much of each they would eat. During the test period, the five species were fed in the same proportions they were consumed in the preliminary period, and the total amount offered was kept just below the level of consumption we had observed. Consequently, virtually all of the offered material was consumed each day throughout the 10 days of the test. To compensate for the time required for material to pass through the digestive tract, fecal material was compared to forage intake observed 48 hours previously (Mautz and Petrides 1971). Since intake was regulated by limiting amounts of each plant in the mix, this precaution was taken primarily to avoid any pretest influence, although in view of the findings of Eng et al. (1964) 48 hours may be insufficient to eliminate all pretest materials. Samples for analysis were composited from all pellet groups deposited cach day.

\section{Results}

Standard deviation indexes $\left(I=\frac{\Sigma(d)^{2}}{n-1}\right.$ Hansen 1971) and coefficients of determination $\left(r^{2}\right)$ were calculated by making paired comparisons of the individual results obtained by the four methods (Table 1). A low index of deviation indicates agreement; a high coefficient of determination does likewise. By both of these indexes, the order of the first three paired comparisons are identical. The other three pairs appear in inverse order, but the differences in each case are small and provide little basis for judgments. Closest agreement was found between diets determined by fecal material collected at a feeding site and utilization estimates made at the same location. This high agreement might have been predicted, for by either method sources of variation are minimized. The samples represent selection of more than a single animal; more than one day's selection was represented at 
Table 1. Comparisons of four methods of diet determination of 14 antelope.

\begin{tabular}{lccc}
\hline \hline & $\begin{array}{c}\text { Deviation } \\
\text { index }\end{array}$ & $\begin{array}{c}\text { Determination } \\
\text { value }\end{array}$ & $\begin{array}{c}\text { Coefficient } \\
\text { rank }\end{array}$ \\
\hline Site feces $\times$ utilization & 5.72 & 0.766 & 1 \\
Rumen $\times$ intestinal feccs & 8.90 & 0.605 & 2 \\
Rumen $\times$ utilization & 10.62 & 0.507 & 3 \\
Intestinal feces $\times$ site feces & 11.54 & 0.394 & 6 \\
Rumen $\times$ site feces & 11.81 & 0.398 & 5 \\
Intestinal feces $\times$ utilization & 11.99 & 0.444 & 4 \\
\hline
\end{tabular}

least on some feeding sites, and on occasion selection was being made from the same plant mix.

Rumen analysis agreed most closely with fecal material from the intestines; rumen analysis and utilization estimates were in third place.

Comparisons based on individual animals are more revealing. In 7 of the 14 individual samples, the results obtained from the rumen agreed very closely both as to species identified and percentage in the sample with the intestinal feces analysis. Since there may be considerable lag between food ingestion and its appearance in the lower intestine, this close agreement indicates constancy in food selection.

In six of the samples, site feces and utilization estimates were very similar and differed somewhat from other methods. Site feces was often intermediately comparable between rumen and intestinal feces on the one hand and vegetation utilization on the other. In one instance site feces agreed most closely with the rumen sample, and intestinal feces was intermediate between rumen and utilization, as it was in four other instances. In four instances rumen diets stood alone; in five instances forage utilization figures differed from all other analytical methods tested.

One measure of the accuracy of the technique for ascertaining diet composition is the number of species identified in the sample; the more species found the more sensitive the method, assuming accuracy in identification. By this criterion, the methods are in descending order rumen, intestinal feces, site feces, and utilization estimates, with mean number of species per sample of 8.7, 8.6, 7.0 and 5.9, respectively. Surprisingly, fewer species were identified in fecal material collected from the ground than in fecal material taken from the intestines. That utilization estimates identified fewer species is not surprising, for the possibility of overlooking light use on quantitatively less important species is high. Moreover, certain plants which readily disarticulate upon being grazed leave almost no visual evidence that cropping has taken place.

The two animals killed at each collection date were insufficient to provide an adequate sample because of individual preference and nonuniformity of vegetation throughout the enclosure. By aggregating the observations from all 14 animals over the entire period, we can in effect enlarge the sample and iron out day-to-day variations. When this was done, there was a high degree of agreement among all methods. In a few instances the percentages differ, but differences are not large, and the results, as shown by the ordination, are almost identical for the

Table 2. Comparison of the diets of male antelope in southwestern Utah for seven periods throughout the summer months as determined by four methods.

\begin{tabular}{|c|c|c|c|c|c|c|c|c|c|c|}
\hline & \multicolumn{2}{|c|}{ Rumen } & \multicolumn{2}{|c|}{ Intestinal feces } & \multicolumn{2}{|c|}{ Site feces } & \multicolumn{2}{|c|}{ Utilization } & \multicolumn{2}{|c|}{ Mean } \\
\hline & Percent & Rank & Percent & Rank & Percent & Rank & Percent & Rank & Percent & Rank \\
\hline \multicolumn{11}{|l|}{ Browse } \\
\hline Prunusfasciculata & 21.7 & 1 & 24.3 & 1 & 25.2 & 2 & 22.5 & 2 & 23.4 & 1 \\
\hline Artemisianova & 17.4 & 2 & 17.7 & 2 & 27.1 & 1 & 27.5 & 1 & 22.4 & 2 \\
\hline Xanthocephalum sarothrae & 11.8 & 3 & 12.4 & 3 & 8.5 & 4 & 6.8 & 4 & 9.9 & 3 \\
\hline Artemisia spinescens & 7.3 & 6 & 7.4 & 5 & 8.5 & 3 & 10.0 & 3 & 8.3 & 4 \\
\hline Ephedra nevadensis & 2.5 & 10 & 3.9 & 8 & 3.2 & 8 & 4.3 & 7 & 3.5 & 8 \\
\hline Juniperus osteosperma & 8.0 & 4 & 5.7 & 6 & 0.1 & 21 & 0.1 & 21 & 3.5 & 9 \\
\hline Brickellia oblongifolia & 6.3 & 7 & 3.9 & 7 & 0.8 & 14 & 1.3 & 12 & 3.1 & 10 \\
\hline Tetradymia nuttallii & 0.7 & 13 & 2.0 & 12 & 2.5 & 9 & 2.9 & $10^{a}$ & 2.0 & 12 \\
\hline Atriplex confertifolia & 1.9 & 11 & 2.5 & 11 & 2.1 & 10 & 1.1 & $13^{b}$ & 1.9 & 13 \\
\hline A. canescens & 0.5 & 17 & 1.2 & 15 & 0.3 & 19 & 0.7 & $16^{c}$ & 0.7 & 15 \\
\hline Cercocarpus intricatus & 0.4 & $18^{d}$ & 0.5 & 16 & 0.5 & 18 & 0.2 & 20 & 0.4 & 18 \\
\hline Cowania stansburiana & 0.3 & 20 & 0.4 & 17 & 0 & & 0.7 & $17^{c}$ & 0.4 & 19 \\
\hline Chrysothamnus spp. & $\mathrm{T}$ & 27 & 0 & & 0.1 & 20 & 0 & & $\mathrm{~T}$ & $27^{e}$ \\
\hline Total browse & 78.7 & & 81.9 & & 78.8 & & 78.1 & & 79.5 & \\
\hline Forbs & & & & & & & & & $\cdot$ & \\
\hline Sphaeralcea spp. & 3.4 & 9 & 7.5 & 4 & 6.6 & 5 & 5.1 & 6 & 5.6 & 5 \\
\hline Salsola kali var. tenuifolia & 5.4 & 8 & 3.5 & 10 & 5.1 & 6 & 6.4 & 5 & 5.1 & 6 \\
\hline Eriogonum spp. & 7.7 & 5 & 3.8 & 9 & 2.0 & 11 & 2.9 & $9^{a}$ & 4.1 & 7 \\
\hline Enceliopsis nudicaulis & 0.8 & 12 & 1.3 & 14 & 1.6 & 12 & 1.1 & $14^{b}$ & 1.2 & 14 \\
\hline Oenothera canescens & 0.3 & 21 & 0 & & 0.6 & 16 & 1.8 & 11 & 0.7 & 16 \\
\hline Chenopodium album & 0.5 & 16 & 0.3 & 18 & 0.5 & 17 & 1.1 & $15^{b}$ & 0.5 & 17 \\
\hline Euphorbia ocellata & 0.2 & 22 & 0.3 & 19 & 0.6 & 15 & 0.3 & 19 & 0.3 & 20 \\
\hline Hermidium alipes & 0.1 & $25^{f}$ & 0.3 & 20 & 1.0 & 13 & 0 & & 0.3 & 21 \\
\hline Penstemon nana & 0.6 & 15 & $\mathrm{~T}$ & 22 & 0 & & 0 & & 0.2 & 22 \\
\hline Hymenopappus filifolius & 0.2 & 23 & 0 & & 0 & & 0.4 & 18 & 0.1 & 23 \\
\hline Chaenactis macrantha & 0.4 & $19^{d}$ & 0 & & 0 & & 0 & & 0.1 & 24 \\
\hline Cryptantha spp. & 0.1 & $26^{f}$ & 0.1 & 21 & 0 & & 0 & & 0.1 & 25 \\
\hline Haploppapus nuttallii & 0.1 & 24 & 0 & & 0 & & 0 & & $\mathrm{~T}$ & $26^{\circ}$ \\
\hline Total forbs & 19.8 & & 17.1 & & 18.0 & & 19.1 & & 18.4 & \\
\hline Grass & 0.7 & 14 & 1.7 & 13 & 3.3 & 7 & 3.0 & 8 & 2.2 & 11 \\
\hline
\end{tabular}


major forage species (Table 2). This suggests that if sufficiently large samples were taken, any of the methods could be expected to be in close agreement.

The results of the controlled feeding tests with deer do not confirm the reliability of the fecal technique. No species appeared in percentages closely approximating its occurrence in the diet (Table 3). Sagebrush (Artemisia tridentata) and juniper (Juniperus osteosperma) were greatly overestimated in the fecal analysis. Both forbs, mulesear (Wyethia amplexicaulis) and desert parsley (Lomatium dissectum), were underestimated considerably. Kentucky bluegrass (Poa pratensis) came closer to agreement, but even it was overestimated by $23 \%$. A paired $t$-test on the fecal-diet estimate comparing the results of the two deer showed highly significant differences $(P \leq .01)$ for all species fed except Lomatium.

A similarity index was calculated using Kulczunski's mathematical index of similarity (Hansen 1971) $S I=\frac{2 w}{a+b}$ where $w$ is the lowest value of percent composition of the actual intake and the dietary estimates and $a+b$ is the sum of the intake estimate and the fecal estimate (Table 3). The index should equal $100 \%$ if the fecal estimate equaled the amount of forage fed (intake estimate). Hansen (1971) considers an index of 85 or better an indication that samples are very much alike. Only with bluegrass did the index of similarity exceed $85 \%$, notwithstanding a paired $t$-test showed a highly significant difference between the amounts of bluegrass in the food feces. These results, though limited, indicate that there is a differential disappearance of epidermal fragments among species.

Table 3. Comparison of percent composition of diets of two mule deer and percentage identified in feces on a dry weight basis.

\begin{tabular}{lcccc}
\hline & $\begin{array}{c}\text { Percent of } \\
\text { diet fed }\end{array}$ & $\begin{array}{c}\text { Diet estimate } \\
\text { using fecal } \\
\text { analysis }\end{array}$ & $t$-values & $\begin{array}{c}\text { Similarity } \\
\text { index, percent }\end{array}$ \\
Species & 9.45 & 28.83 & $19.71^{* *}$ & 46.57 \\
\hline $\begin{array}{l}\text { Artemisia } \\
\quad \text { tridentata }\end{array}$ & 39.52 & 24.57 & $13.30^{* *}$ & 76.67 \\
$\begin{array}{l}\text { Wyethia } \\
\quad \text { amplexicaulis }\end{array}$ & 33.03 & 22.33 & 9.43 & 80.69 \\
$\begin{array}{l}\text { Lomatium } \\
\text { dissectum }\end{array}$ & 17.67 & 21.66 & $4.53^{* *}$ & 89.91 \\
$\begin{array}{l}\text { Poapratensis } \\
\text { Juniperus } \\
\quad \text { osteosperma }\end{array}$ & 0.34 & 3.07 & $7.66^{*}$ & 20.65 \\
\hline
\end{tabular}

Significantly different at .01 level.

\section{Discussion}

The results we obtained suggest the claims for accuracy of the fecal analysis technique made by some investigators are overstated. In those studies where close agreement between observed intake and fecal fragments identified have been reported, grasses provided the sole or major part of forage ingested. Similarities between species with respect to cutinization, fragmentation on digestion, rate of digestion, and ratio of epidermis to volume of plant tissue could thus be expected to be quite similar among species. When dissimilar plants such as forbs and browse have been involved, the results have been disappointing (Jacobs 1975; Slater and Jones 1971; Westoby et al. 1976). Dunnet et al. (1973) found different digestibilities (as determined by "persistence indexes") due to plant species, individual animal, and feeding trial. Voth and Black (1973) ascertained that among 20 species eaten by mountain beaver the ratios of fecal fragments identified to the weight of material consumed varied from 0.9 to 14.6 . No grasses were included nor does it appear that the fecal material was ground prior to analysis, a procedure that might be expected to reduce variability in the size of epidermal fragments, and hence, the range of fragment to weight ratios.

The marked differences in the results from individual animals as shown by the method of analysis used-rumen material, fecal material, or utilization estimates of vegetation-are not surprising, since to a considerable extent they did not represent samples from the same population. Had the animals been confined to a homogeneous plant community for a period of 2 or 3 days, one could have expected greater agreement. In fact there were several factors which affected agreement among the samples obtained. In some cases there was evidence that the site where animals were located and from which samples were obtained had been occupied for a day or more. Under these conditions, the results could be expected to be similar, and any differences would reflect the method of analysis. If, however, animals had just moved to the site from grazing another plant community, the fecal material, whether obtained from the intestine or picked up on the site, would represent vegetation from areas previously grazed and which may have been unlike that found at the collection site. Rumen material and intestinal feces represént a much shorter feeding interval than other data sources

It is difficult to explain why utilization and rumen data were not more often similar, for they ought in most cases to have come from the same population. We killed animals only after they had been observed feeding for some time; hence estimates of forage removal should have matched material in the rumen unless the animals had fed elsewhere before we located them, in which case items other than those on site could have been ingested. In addition, coarser material may be retained in the rumen, thus exaggerating its importance.

Although there are reasons, such as mobility of the animals and a more restricted sample from the intestine, why results from intestinal fecal material would differ from results from fresh fecal material collected from the ground, it is surprising that they differed so often. For example, the coefficient of determination between site feces and intestinal feces was 0.646; between site feces and forage utilization it was 0.766 (Table 1).

Fewer species were identified from fecal material collected from the ground than from intestinal feces, in aggregate 23 species. Since the intestinal feces came from the rectum, there should have been little difference in the digestion processes in each case. Possibly the weathering that feces were subjected to after being deposited may have been a factor, although we collected only the fresher-appearing feces. We have in other studies where intakes were known, experienced difficulty in identifying some species in fecal matter. We are not yet certain whether this was due to alterations in diagnostic characteristics caused by digestion or whether the preparation procedures used were responsible.

Our decision to analyze intestinal feces was based on a "target of opportunity" concept. It is unlikely that wild animals would be sacrificed to obtain fecal material solely for food habits analysis. In view of the fact that in our experience the results from intestinal feces closely paralleled rumen analysis, there seems no impelling reason to make fecal examination of intestinal material, although to do so would theoretically broaden the base of the sample (by covering a larger time interval) and provide a more representative sample. Each animal might thus provide samples from two or more feeding 
days rather than just one.

Only in a general way do the data in Table 2 provide an index of the species consumed by antelope on the western desert valleys of Utah in summer. The vegetation in the enclosure in which the herd was confined is not entirely representative of that found elsewhere. There is more desert almond (Prunus fas(iculata) than is found in many areas and forbs are better represented than in many adjoining areas both in number of species and amounts produced. Secondly, no collection was made in May, which tends to depress the importance of forbs in the diet since it is then that forb production is ordinarily highest. Also, bug sage (Artemisia spinescens), a highly preferred plant of pronghorn, is of great importance in May. Finally, the animals taken in late July and August were found in portions of the enclosure where black sage (Artemisia nova) was not present. This probably accounts for this species being in second place; examination of stomach contents of free-roaming pronghorn killed during the hunting season in August in areas adjacent to the station enclosure showed that black sage was over three times as important as desert almond. In part this may be due also to unavailability of desert almond in some areas from which the hunted animals came.

Our results as well as those of others which have been reported suggest that additional work must be done before the fecal analysis technique can be evaluated as a method for quantifying ruminant diets. Several factors account for this. Different plant species respond differently to the digestion process. Some species may become unidentifiable in the feces (Slater and Jones 1971). Others, though identifiable, are differently fragmented so that, if fragment counts are used as a basis for determination, the proportions of species appear different. This factor is especially important where plants of very dissimilar kinds having different epidermal characteristics are involved. For example, Owen (1975) observed marked differences in fragmentation among three grass species eaten by waterfowl.

Determining leaf area: weight ratios may solve the fragmentation problem, though there are disparities among different kinds of material from the same plant (Owen 1975) and among plants (Dunnet et al. 1973). Moreover, determinations of leaf area are not readily made. The results of these factors may require determination of conversion factors. Even so, such "equivalence factors" may have a 15-fold range (Voth and Black 1973). In addition to plant differences, the effects on the ingested material may differ among animals. In July, the amounts of Themeda triandra were less in the feces than in the feed of zebra and greater in the case of wildebeest and kongoni (Casebeer and Koss 1970).

Finally, the preparation of material is vitally important. The widely differing preparational procedures reported in the literature are evidence of dissatisfaction with procedures reported by others. This was our experience. It would be instructive to determine how the different preparational techniques that have been suggested affect the results obtained.

We conclude that until more is known about the effect the factors described above have on results, the determination of diets from fecal analysis must be regarded as qualitative rather than quantitative (see also Vavra et al. 1978). Moreover, it is time consuming, requires laboratory facilities, and experience.
Despite these problems it may be a useful supplement to utilization estimates and other observational methods for obtaining dietary estimates of furtive and difficult-to-observe species.

\section{Literature Cited}

Anthony, R.G., and N.S. Smith. 1974. Comparison of rumen and fecal analysis to describe deer diets. J. Wildl. Manage. 38:535-540.

Baumgartner, L.L., and A.C. Martin. 1939. Plant histology as an aid in squirrel food-habitat studies. J. Wildl. Manage. 3:266-268.

Casebeer, R.L., and G.G. Koss. 1970. Food habits of wildebeest, zebra, hartebeest and cattle in Kenya Masailand. E. Afr. Wildl. 8:25-36.

Cavender, B.R., and R.N. Hansen. 1970. The microscopic method used for herbivore diet estimates and botanical analysis of litter and mulch at the Pawnee Site. Grassland Biome Tech. Rep. 18. 9 p.

Chamrad, A.D., and T.W. Box 1964. A point frame for sampling rumen contents. J. Wildl. Manage. 28:473-477.

Croker, B.H. 1959. A method of estimation of the botanical composition of the diet of sheep. N.Z. J. Agr. Res. 2:72-85.

Dunnet, G.M., A.E. Harvie, and J.T. Smit. 1973. Estimating the proportions of various leaves in the diet of the opossum, Trichosurus vulpecula Kerr, hy faecal analysis. J. Appl. Ecol. 10:737-745.

Dusi, J.L. 1949. Methods for the determination of food habits by plant microtechniques and histology and their application to cottontail rabbit food habits. J. Wildl. Manage. 13:295-298.

Eng, K.S., Jr., M.E. Riewe, J.H. Craig, Jr., and J.C. Smith. 1964. Rate of passage of concentrate and roughage through the digestive tract of sheep. J. Animal Sci. 23:1129-1132.

Free, J.C., R.M. Hansen, and P.L. Sims. 1970. Estimating dry weights of food plants in feces of herbivores. J. Range Manage. 23:300-302.

Hansen, R.M. 1971. Estimating plant composition of wild sheep diets. First Trans. North Amer. Wild Sheep Conf. 180-115

Hercus, B.H. 1960. Plant cuticle as an aid to determining the diet of grazing animals. 8th Int. Grassland Cong. Proc. 443-447.

Jacobs, J. 1973. A microtechnique index to pronghorn diet and sagebrush coefficients. Job Completion Report, Wyoming Pittman-Robertson Proj. FW-3-R-20. Processed. 49 p.

Marshall, J.W. 1969. Assessment of the accuracy of quantitative methods of determining the diet selected by herbivores. Arid Zone Newsletter. p. $1+1-1+2$

Martin, D.J. 1955. Features of plant cuticle-an aid to the analysis of the natural diet of grazing animals, with special reference to Scottish hill sheep. Trans. and Proc. Bot. Soc. Edinburg. 36:278-288.

Mautz, W.W., and G.A. Petrides. 1971. Food passage rate in whitetailed deer. J. Wildl. Manage. 35:723-731.

Owen, M. 1975. An assessment of fecal analysis technique in waterfowl feeding studies. J. Wildl. Manage. 39:271-279.

Shandruk, L.J. 1975. A comparison of three methods used to analyze pronghorn antelope diets. Unpublished MS Thesis, Utah State Univ. Logan. $109 \mathrm{p}$.

Slater, Joanna, and R.J. Jones. 1971. Estimation of the diets selected by grazing animals from microscopic analysis of the faeces-a warning. $\mathbf{J}$. Australian Inst. Agr. Sci. 37:238-239.

Stewart, D.R.M. 1967. Analysis of plant epidermis in faeces: A technique for studying food preferences of grazing herbivores. J. Appl. Ecol. 4:82-111.

Storr, G.M. 1961. Microscopic analysis of faeces, a technique for ascertaining the diet of herhivorous mammals. Aust. J. Bio. Sci. 14:157-164.

Vavra, M., R.W. Rice, and R.M. Hansen. 1978. A comparison of esophageal fistula and fecal material to determine steer diets. J. Range Manage. $31: 11-13$.

Voth, E.H., and H.C. Black. 1973. A histologic technique for determining feeding habits of small herbivores. J. Wildl. Manage. 37:223-231.

Westoby, M., G.R. Rost, and J.A. Weis. 1976. Problems with estimating herbivore diets by microscopically identifying plant fragments from stomachs. J. Mammal. 57:167-172.

Williams, O.B. 1969. An improved technique for identification of plant fragments in feces. J. Range Manage. 22:51-52.

Zyznar, E., and P.J. Urness. 1969. Qualitative identification of forage remnants in deer feces. J. Wildl. Manage. 33:506-510. 